\title{
Characterization of Amorphous Tantalum Oxide for Insulating Acoustic Mirrors
}

\author{
J. Capilla, J. Olivares, M. Clement, J. Sangrador \\ and E. Iborra \\ Grupo de Microsistemas y Materiales Electrónicos. \\ Universidad Politécnica de Madrid \\ Madrid, Spain \\ eiborra@etsit.upm.es
}

\author{
A. Devos \\ IEMN Dpt ISEN, UMR CNRS 8520 \\ Lille, France \\ Arnaud.devos@isen.fr
}

\begin{abstract}
This work describes the assessment of the acoustic properties of sputtered tantalum oxide films intended as high impedance films for the acoustic isolation of bulk acoustic wave devices operating in the $\mathrm{GHz}$ frequency range. The films are grown by sputtering a metallic tantalum target under different oxygen and argon gas mixtures, total pressures, pulsed DC powers and substrate bias. The structural properties of the films are assessed through infrared absorption spectroscopy and $X$ ray diffraction measurements. Their acoustic impedance is obtained after estimating the mass density by X-ray reflectometry measurements and the longitudinal acoustic velocity by analyzing the longitudinal $\lambda / 2$ resonance induced in a tantalum oxide film inserted between an acoustic reflector and an AIN-based resonator. A second measurement of the sound velocity is achieved through picosecond acoustic spectroscopy.
\end{abstract}

\section{INTRODUCTION}

Bulk acoustic wave resonator technology is a recent solution for low cost, high performance bandpass filters for digital wireless communications, such as wireless networking, cellular phones, or global positioning systems. These filters are composed of several resonators electrically connected to obtain the desired filter characteristics. To obtain wellperforming devices, a good acoustic isolation of the resonators is required to avoid energy losses through the substrate that reduce their quality factor. There are two typical methods to achieve a good acoustic isolation. The first one consists in creating an air gap between the resonator and the substrate; as the acoustic radiation to the air is minimal, energy losses can only take place through the supports. These structures, called film bulk acoustic resonators (FBAR), have some drawbacks, as a complex fabrication technology or a too high thermal isolation that limits the power handling. The alternative method is the use of acoustic reflectors between the resonators and the substrate; the resulting structures are called solidly mounted resonators (SMR) [1]. Bragg mirrors are typical acoustic reflectors formed by alternating a quarter wavelengththick layers $(\lambda / 4$-layers) of low and high acoustic impedance [2]. The acoustic isolation achieved (reflection coefficient) increases with the number of layers and the mismatch between the acoustic impedances of two consecutive layers. Considering that the acoustic impedance of a given material is the product of the longitudinal sound velocity and the mass density, these two material properties have to be perfectly known in order to set the thickness of the films to $\lambda / 4$ to get the targeted resonant frequency and to fix the number of layers required for a specified mirror reflectance. Table I summarizes the experimental values of such material properties for the most commonly used acoustic mirrors constituents.

$\begin{array}{cccc}\text { TABLE I. } & \text { ACOUSTIC IMPEDANCE OF METALLIC AND INSULATING } \\ \text { MATERIALS }\end{array}$

Silicon dioxide $\left(\mathrm{SiO}_{2}\right)$ layers are commonly used as low acoustic impedance material, owing to their easy processing and full compatibility with standard silicon technologies [3]. Other low impedance materials are aluminum (Al) [4] and silicon oxicarbide (SiOC) [5], although they are less frequently used due to the metallic character of $\mathrm{Al}$ and the elevated acoustic losses of SiOC. On the other hand, materials with high acoustic impedance are typically high density metals exhibiting, additionally, a moderate sound velocity, such as iridium (Ir) [6], molybdenum (Mo) [7], or tungsten (W) [8]. If these high impedance layers are substituted by insulating films, the fabrication process of BAW filters can be 
significantly simplified, as there is no need to define the continuous metallic layers that short circuit the different resonators built on top of the same acoustic mirrors. Achieving insulating Bragg mirrors requires, thus, high acoustic impedance insulating layers, which are unfortunately not easily available. So far, insulating acoustic mirrors have been obtained by combining $\mathrm{SiO}_{2}$ or $\mathrm{SiOC}$ layers with aluminum nitride (AIN) [9], silicon nitride $\left(\mathrm{Si}_{3} \mathrm{~N}_{4}\right)$ [5] or tantalum oxide $\left(\mathrm{Ta}_{2} \mathrm{O}_{5}\right)[10,11]$, although the acoustic properties of this last have not been extensively characterized. However, none of these three materials exhibits really high acoustic impedances, in comparison with that offered by high density metallic layers. The considerably large acoustic velocity of AlN combined with a low mass density (see table I) provides a moderate acoustic impedance. On the other hand, $\mathrm{TaO}_{\mathrm{x}}$ films offer similar acoustic impedance than AlN by virtue of its high mass density, although the sound velocity appears to be considerably smaller.

In this work we have characterized the acoustic properties of $\mathrm{TaO}_{\mathrm{x}}$ films in order to investigate whether these layers, in combination with $\mathrm{SiO}_{2}$ films, may provide better acoustic isolation than $\mathrm{SiO}_{2} / \mathrm{AlN}$-based Bragg mirrors. The structure, mass density and sound velocity of sputtered $\mathrm{TaO}_{\mathrm{x}}$ films have been assessed by different techniques, which include the fabrication and characterization of specific devices for the evaluation of the sound velocity.

\section{EXPERIMENTAL}

\section{A. Sputtering Process}

$\mathrm{TaO}_{\mathrm{x}}$ films were deposited in a Leybold Z-550 system by pulsed-DC magnetron sputtering of a $150 \mathrm{~mm}$-wide Ta target in $\mathrm{Ar} / \mathrm{O}_{2}$ admixtures. A pulsed-DC power of $50 \mathrm{kHz}$ and duty cycle $75 \%$ was applied to the target. More than 150 films were deposited under different conditions by varying the total pulsed-DC power between $500 \mathrm{~W}$ and $1200 \mathrm{~W}$, the total pressure in the chamber between $1.5 \mathrm{mT}$ orr and $3.3 \mathrm{mT}$ orr and the percentage of $\mathrm{O}_{2}$ in the gas between $30 \%$ and $100 \%$. An $\mathrm{RF}$ source was used to polarize the substrate between $-50 \mathrm{~V}$ (with no RF power applied to it) and $-150 \mathrm{~V}$. The substrates were not intentionally heated during deposition.

The sputter process of a Ta metallic target in $\mathrm{Ar} / \mathrm{O}_{2}$ atmospheres shows a transitory behavior owing to the oxidation of the target. When bombarding a clean metallic surface at constant power with a gas containing a certain amount of oxygen, the time to stabilize the plasma impedance can reach several hours. In order to guarantee that the target had reached a stationary state before starting deposition, the target was first preconditioned at the deposition power in pure oxygen atmosphere; the voltage of the cathode attained a constant value after around $15 \mathrm{~min}$, when the plasma impedance reached the steady state. The selected gas mixture was then fed into the chamber at the chosen pressure and the voltage of the cathode controlled until the new steady state was attained ( 15 to $30 \mathrm{~min}$ ). At this moment the shutter was opened for film deposition during the desired time. Subsequent depositions under identical conditions required only a few minutes for stabilization. Every time the deposition conditions were modified, the complete conditioning process was restarted. The $\mathrm{TaO}_{\mathrm{x}}$ films were deposited on (100) silicon wafers for IR transmission measurements and on acoustic reflectors (described below) built on top of silicon substrates for the assessment of the sound velocity through the frequency response of test solidly mounted resonators (SMR).

\section{B. Film characterization}

The structure and morphology of the $\mathrm{TaO}_{\mathrm{x}}$ were assessed by infrared transmission measurements carried out with a Fourier transform infrared (FTIR) Nicolet 5-PC spectrophotometer, which provided the chemical bonding configuration of the films. We used non-polarized light at normal incidence over the $400 \mathrm{~cm}^{-1}$ to $4000 \mathrm{~cm}^{-1}$ range with a spectral resolution of $4 \mathrm{~cm}^{-1}$. The absorption bands corresponding to the $\mathrm{Si}$ substrate were eliminated by subtracting the absorbance spectrum measured in bare Si. X-ray diffraction patterns were measured in conventional Bragg-Brentano geometry in a Supratech XPert MRD diffractometer between $2 \theta=10^{\circ}$ and $2 \theta=80^{\circ}$.

The assessment of the acoustic properties of $\mathrm{TaO}_{\mathrm{x}}$ films requires very precise measurements of their mass density, acoustic velocity and thickness. The thickness of the $\mathrm{TaO}_{x}$ films and that of the other films involved in test devices were measured with a Veeco Dektak 150 profilometer. The density of the $\mathrm{TaO}_{\mathrm{x}}$ layers was assessed by X-ray reflectometry (XRR) measurements using the same diffractometer operated at grazing incidence between $0.05^{\circ}$ and $2.5^{\circ}$. Finally, the longitudinal sound velocity was assessed using two different techniques. First, the sound speed was measured in different test structures by the picosecond ultrasonic technique [12]. A second assessment was deduced from the frequency response of the electrical impedance of specific SMR test devices containing the $\mathrm{TaO}_{\mathrm{x}}$ layers under study, measured with an Agilent PNA N5230A network analyzer. The $\mathrm{TaO}_{\mathrm{x}}$ films, with thickness ranging between $150 \mathrm{~nm}$ and $1000 \mathrm{~nm}$, were inserted between a well characterized acoustic reflector composed of four alternated porous- $\mathrm{SiO}_{2}$ and $\mathrm{Mo}$ films and a $\mathrm{Mo} / \mathrm{AlN} / \mathrm{Mo}$ resonator, as shown in Fig. 1. The excitation of the resonator induced a $\lambda / 2$ resonance in the $\mathrm{TaO}_{\mathrm{x}}$ film. The fitting of the experimental data with Mason's model allowed deriving the longitudinal acoustic velocity, provided that the material properties and the thickness of all the layers involved in the device were known.

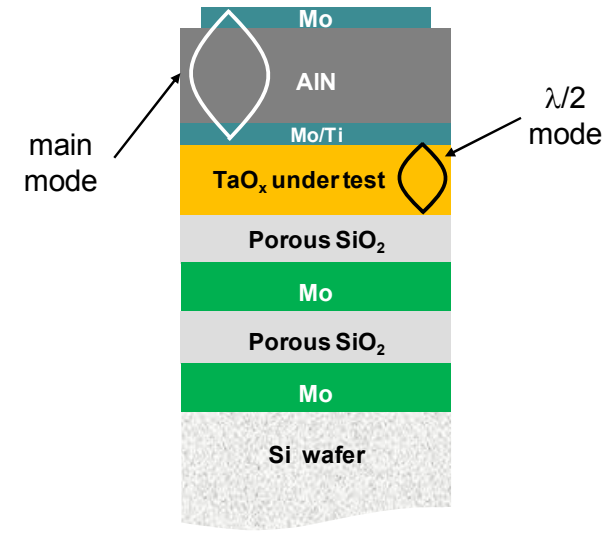

Figure 1. Sketch of the test devices used for assessing the sound velocity in sputtered $\mathrm{TaO}_{\mathrm{x}}$ films. The main resonant mode in the piezoelectric stack is represented in white, and the $\lambda / 2$ mode in the $\mathrm{TaO}_{\mathrm{x}}$ film in black. 


\section{RESULTS AND DISCUSSION}

\section{A. Structure and Composition of Sputtered Tantalum Oxides}

Fig. 2 shows the IR transmission spectra of three $\mathrm{TaO}_{\mathrm{x}}$ of different thickness. The bands at $950 \mathrm{~cm}^{-1}$ and $650 \mathrm{~cm}^{-1}$ have been associated to the Ta-O-Ta stretching mode and the $\mathrm{O} \equiv \mathrm{Ta}$ bond, respectively, of amorphous $\mathrm{TaO}_{x}$ films [13]. The main absorption band at $650 \mathrm{~cm}^{-1}$ has been reported to shift to lower wavenumbers (down to $510 \mathrm{~cm}^{-1}$ ) in polycrystalline films. In our spectra this band appears as a shoulder in the $530 \mathrm{~cm}^{-1}$ region. The spectra suggest that our $\mathrm{TaO}_{\mathrm{x}}$ films are mainly amorphous, but contain a certain amount of microcrystals. Considering the amplitude ratio of the bands at $530 \mathrm{~cm}^{-1}$ and $650 \mathrm{~cm}^{-1}$ as a qualitative estimation of the amount of microcrystals embedded in the amorphous matrix, a slight increase is observed with the thickness of the films. However, in films of similar thickness, we have not observed any clear dependence between the amount of microcrystals and the deposition conditions.

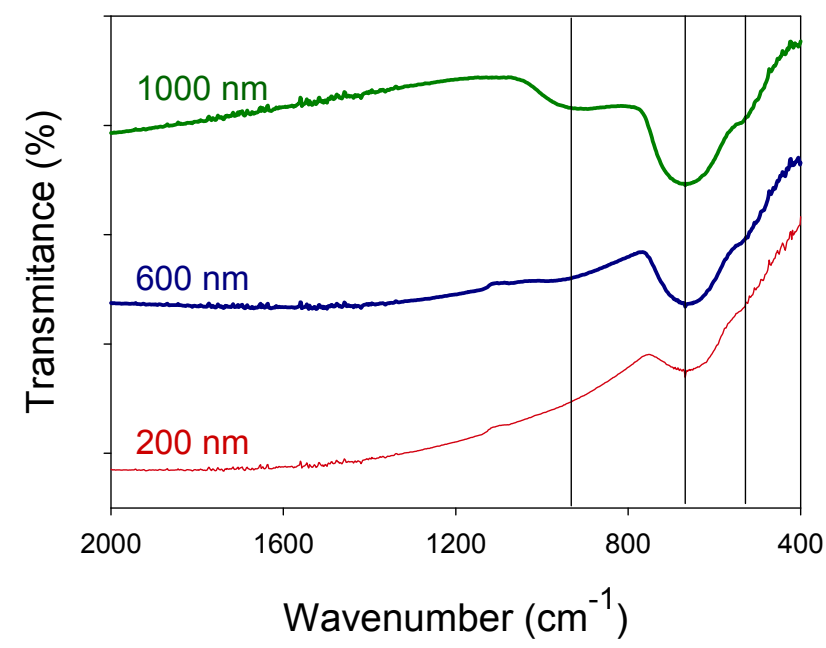

Figure 2. Infrared transmision spectra between $2000 \mathrm{~cm}^{-1}$ and $400 \mathrm{~cm}^{-1}$ of three $\mathrm{TaO}_{\mathrm{x}}$ films of different thickness.

X-ray diffraction measurements confirm this behavior. Fig. 3 shows the XRD patterns of the three $\mathrm{TaO}_{\mathrm{x}}$ films of different thickness analyzed by FTIR. It is important to note that, among all the films deposited, only a few exhibited clear XRD peaks corresponding to the orthorhombic $\beta$-phase of $\mathrm{Ta}_{2} \mathrm{O}_{5}$, whereas most of the films deposited in similar conditions were clearly amorphous. Peaks at $2 \theta=26^{\circ}, 52^{\circ}, 48^{\circ}, 56^{\circ}$ and $62^{\circ}$ corresponding to the (210), (200), (3121), (200), and (201) directions of the $\mathrm{Ta}_{2} \mathrm{O}_{5}$ orthorhombic $\beta$-phase appear in the patterns corresponding to the thicker films, whereas no traces of these peaks are visible in the thinner one, which indicates its amorphous character. Additional peaks corresponding to AlN and Mo are also observed, as the films are characterized after depositing the piezoelectric stack for electric characterization. The data suggest again that thicker films tend to contain some nanocrystals whose grain size, derived from the width of the $\mathrm{TaO}_{\mathrm{x}}$ peaks, is around $10 \mathrm{~nm}$. However, we have not found any clear trend between the microcrystalline character of the samples (or any other film property) and the deposition conditions.

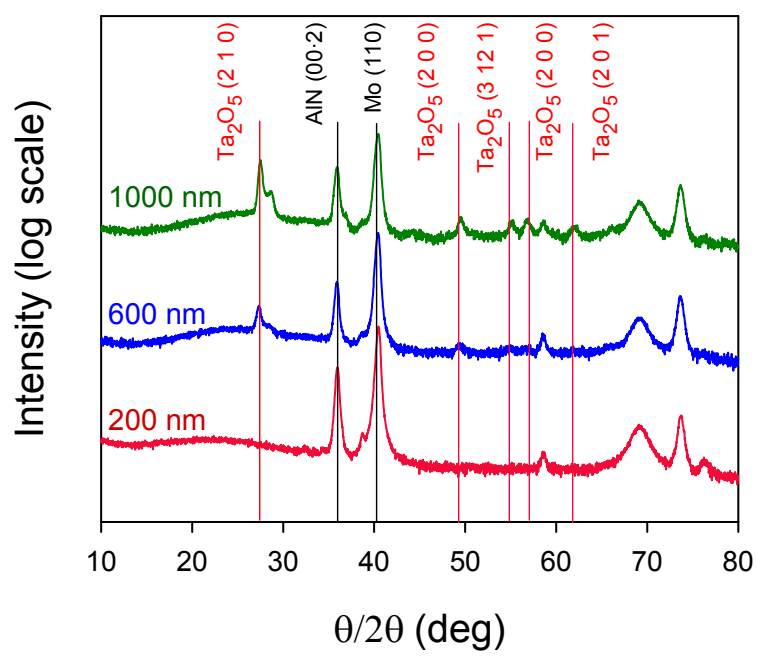

Figure 3. XRD patterns of $\mathrm{TaO}_{\mathrm{x}}$ films of different thickness.

\section{B. Density assessment}

The mass density $\rho$ of the $\mathrm{TaO}_{\mathrm{x}}$ films was measured by XRR, which provides a direct assessment of $\rho$ independently of the thickness. X-rays impinging on smooth $\mathrm{TaO}_{\mathrm{x}}$ surfaces at grazing incidence below a critical angle $\theta_{c}$ are totally reflected. When the incident angle exceeds $\theta_{c}$, the X-rays penetrate into the film and the intensity of the reflected beam drops sharply. According to [14], the $\rho$ can be obtained through the measured $\theta_{\mathrm{c}}$. The XRR patterns of the densest and less dense $\mathrm{TaO}_{\mathrm{x}}$ films are shown in Fig. 4; the patterns of all the remaining films lie between these two traces. The experimental data were fitted using the commercial software RCREFSimW from IHP [15] which provided an accurate value of $\rho$. The values obtained were $8100 \mathrm{~kg} / \mathrm{m}^{3}$ and $7300 \mathrm{~kg} / \mathrm{m}^{3}$, respectively, revealing that even the denser films do not reach the nominal mass density of $\mathrm{Ta}_{2} \mathrm{O}_{5}\left(8200 \mathrm{~kg} / \mathrm{m}^{3}\right)$. These low values of $\rho$ could be associated either to a lack of stoichiometry (films containing oxygen in excess) or more likely to a non-packed structure associated to the amorphous structure of most of the films. The high value of the refractive index (2.26) measured at a wavelength of $400 \mathrm{~nm}$ confirms this hypothesis.

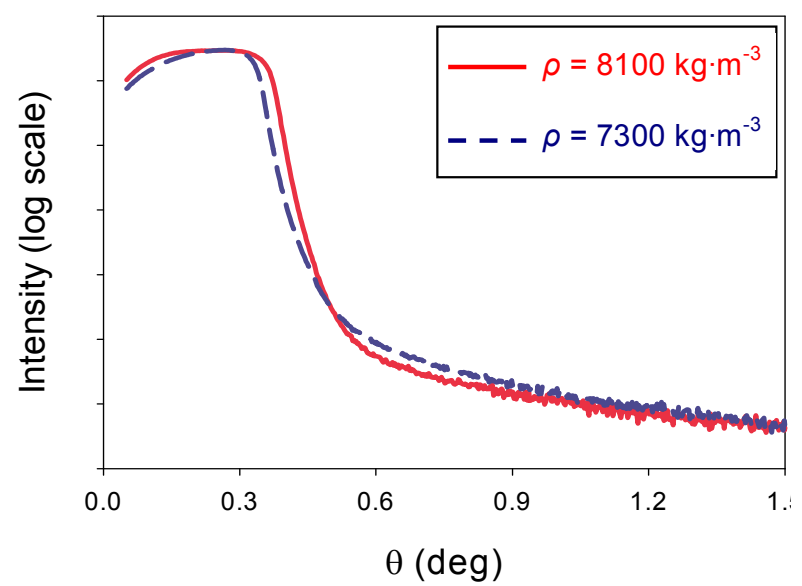

Figure 4. X-ray reflection curves of two $200 \mathrm{~nm}$-thick TaOx films grown on acoustic reflectors. The red solid line corresponds to the film of highest mass density and the blue dashed line to the film of lowest mass density. 


\section{Sound Velocity Assessment}

1) Assessment through test SMRs: The first way to assess the longitudinal sound velocity in the $\mathrm{TaO}_{\mathrm{x}}$ films consisted in the measurement of the $\lambda / 2$ resonant mode induced in these layers when they were placed in intimate contact with a piezoelectric resonator, as shown in Fig. 1. Taking into account that the wavelength of the stationary wave of this mode is ideally twice the thickness of the layer, the sound velocity $v_{\mathrm{s}}$ can be estimated, in a first approach, from the resonant frequency $f_{0}$ of the $\lambda / 2_{\mathrm{TaOx}}$ and the thickness $t$ of the layer through:

$$
v_{s}=f_{0} \times 2 \cdot t
$$

However, as the resonant frequency also depends on the weight of the different layers involved in the test SMR, reliable values of the longitudinal sound velocity were only achieved if the whole experimental frequency response of the test resonator was fitted with Mason's physical model [16].

The variation with frequency of the modulus of the electrical impedance of two test SMR containing $\mathrm{TaO}_{\mathrm{x}}$ layers of different thickness is shown in Fig. 5. Two resonances appear in each spectrum at different frequencies. The low frequency modes correspond to the main resonance in the AlN layer whereas the high frequency modes are associated with the $\lambda / 2$ mode in the $\mathrm{TaO}_{\mathrm{x}}$ film. Fig. 5 shows that upon decreasing the thickness of the $\mathrm{TaO}_{\mathrm{x}}$ film, the two main resonances shift to higher frequencies, because the weight of this layer decreases and influences the travel of the wave in the whole structure.

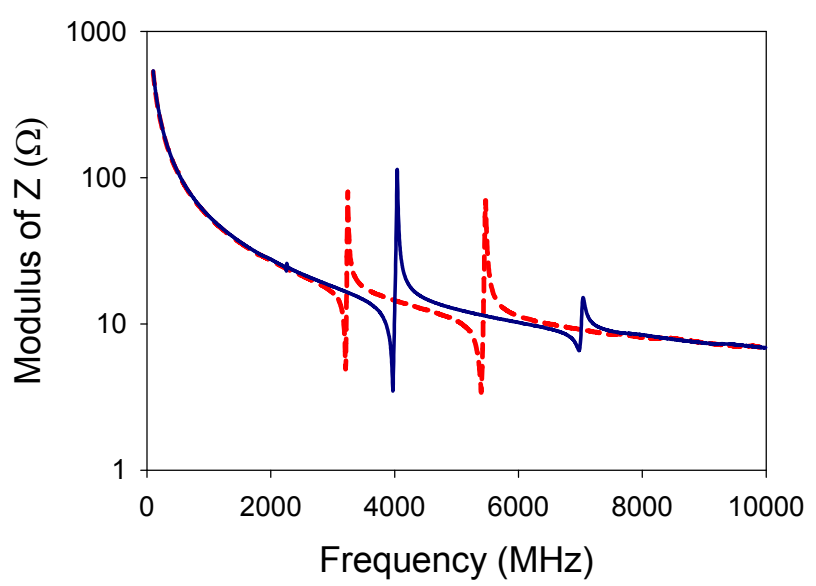

Figure 5. Modulus of the impedance versus frequency of two identical test SMRs containing $180 \mathrm{~nm}$-thick (blue solid line) and $400 \mathrm{~nm}$-thick (red dashed line) $\mathrm{TaO}_{\mathrm{x}}$ films.

Fitting the experimental data to Mason's model requires precise values of the material properties of all layers involved in the test structures and of all the dimensions of the devices (thickness of layers and areas of the resonators). The area of the top electrode, which defined the areas of the SMRs, was measured carefully with an optical microscope to avoid errors due to the undercutting during the electrode definition. The properties of the different materials used for fitting the experimental data are listed in Table II. Data of Mo and AIN were taken from the literature and those of porous $\mathrm{SiO}_{2}$ had been carefully characterized in a previous work [17]. Besides, all these layers have been routinely tested in other devices that do not contain $\mathrm{TaO}_{\mathrm{x}}$ films.

TABLE II. MATERIAL CONSTANTS FOR SMR MATERIALS

\begin{tabular}{ccc}
\hline \hline Material & $\mathbf{v}_{\mathbf{S}}(\mathbf{m} / \mathbf{s})$ & $\boldsymbol{\rho}\left(\mathbf{k g} / \mathbf{m}^{-3}\right)$ \\
\hline \hline $\mathrm{Mo}$ & 5500 & 10500 \\
$\mathrm{SiO}_{2}$ & 5350 & 1900 \\
$\mathrm{AlN}$ & 11000 & 3300 \\
\hline \hline
\end{tabular}

The fitting of the experimental data of Fig. 5 allowed deducing the value of the longitudinal sound velocity of the different $\mathrm{TaO}_{\mathrm{x}}$ layers, which are presented in Fig. 6. The dispersion observed is very likely due to the structural variations of the $\mathrm{TaO}_{\mathrm{x}}$ films revealed by XRD and FTIR.

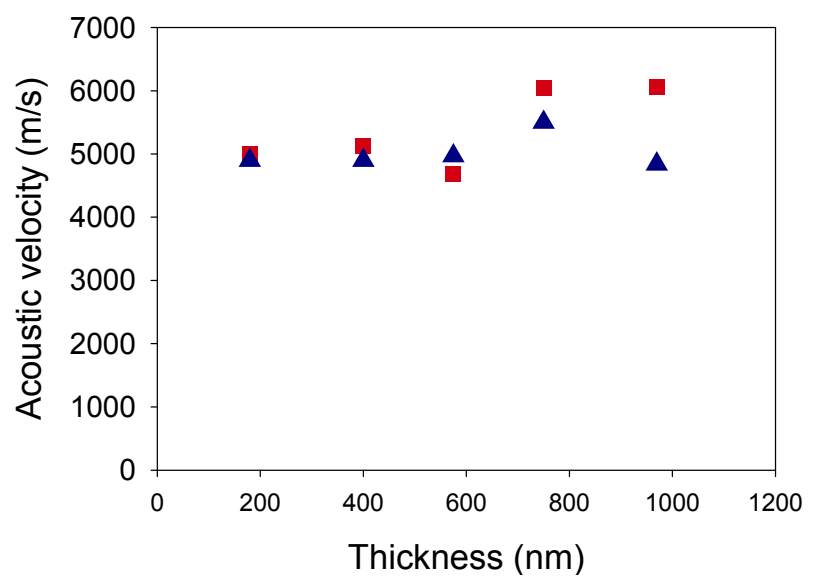

Figure 6. Sound velocity of a set of $\mathrm{TaO}_{\mathrm{x}}$ of different thicknesses grown under identical conditions. BAW devices measurements $(\boldsymbol{\Delta})$ and picosecond ultrasonics measurements ( $\square)$.

2) Assessment through picosecond measurements: An alternative way of assessing the sound velocity is by the picosecond ultrasonic technique [18]. In this technique, a pump laser pulse heats the surface of the metallic layer producing a local dilatation. This generates a very high frequency longitudinal strain wave that propagates through the film to the surface at the longitudinal sound velocity. Two different methods were used to detect acoustic waves.

In the first method we detect the arrival of the acoustic pulse in the substrate. Assuming the thickness of the layer is known, the longitudinal acoustic velocity is obtained by dividing the thickness $d$ by the time of transit $\tau$ of the echo:

$$
v_{s}=\frac{d}{\tau}
$$

In the second method and as the strain wave propagates through the transparent film, it causes local variations of the refractive index. These changes can be detected by a second light beam, called the beam probe. The beam probe reflected at the surface of the films interferes with the beam reflected at the front of the traveling strain wave, causing the intensity of 
the signal in the detector to oscillate with time. The period $T$ of the so-called Brillouin oscillations is directly related to the longitudinal sound velocity through the equation,

$$
v_{s}=\frac{\lambda}{2 n T \cos \theta}
$$

where $\lambda$ is the probe wavelength, $n$ the refractive index of the dielectric layer at $\lambda$ and $\theta$ the incident angle $[19,20]$.

The measurements were carried out on test structures composed of $\mathrm{TaO}_{\mathrm{x}}$ layers of different thicknesses deposited on top of bare silicon substrates. A thin Al layer was deposited on the $\mathrm{TaO}_{\mathrm{x}}$ film to allow the pumping pulse to be absorbed. The picosecond acoustic response of a representative sample is presented in Fig. 7, showing the first echo of the acoustic pulse at $133 \mathrm{ps}$ and the period of the Brillouin oscillations of 20.3 ps. The value of the refractive index (2.26) at the laser probe wavelength $(400 \mathrm{~nm})$ was measured by ellipsometry. The acoustic velocity of this particular sample calculated by the two methods is $4500 \mathrm{~m} / \mathrm{s}$.

The sound velocities obtained by this technique are depicted in Fig. 6 together with those obtained by the BAW resonator fitting method. The results suggest that the sound velocity tends to increase with the thickness of the films, which would be in agreement with the nanocrystallites observed in the thicker films by XRD. They also reveal some discrepancies between the values achieved with the two techniques, especially for the thicker films. This can be due to the fact that the two techniques use different layered structures; whereas the $\mathrm{TaO}_{\mathrm{x}}$ films assessed through the $\mathrm{BAW}$ test devices are grown on $\mathrm{SiO}_{2}$ layers, those assessed by the picosecond measurements are grown on crystalline $\mathrm{Si}$ substrates. The structural differences of the underlying substrates may have affected the crystalline properties of the $\mathrm{TaO}_{\mathrm{x}}$ films, and hence their sound velocities. Other picosecond measurements performed in $\mathrm{TaO}_{\mathrm{x}}$ films deposited on molybdenum films yield sound velocities slightly greater than those achieved on $\mathrm{Si}$ substrates, which confirms the influence of the substrate on the $\mathrm{TaO}_{\mathrm{x}}$ deposition.

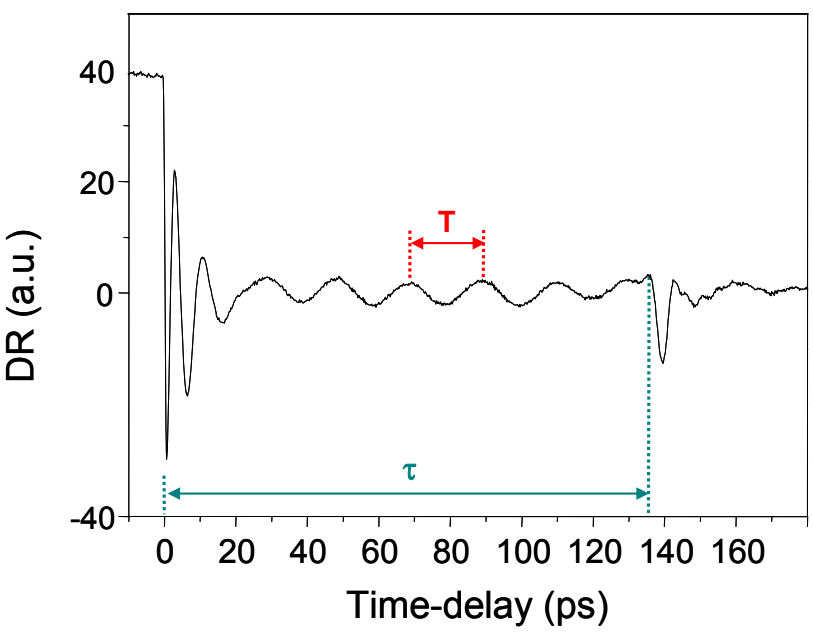

Figure 7. Picosecond acoustic response of a $\mathrm{Al} / \mathrm{TaO}_{\mathrm{x}} / \mathrm{Si}$ structure showing the Brillouin oscillations of period T and the time of transit of the echo $\tau$.
In order to investigate whether these $\mathrm{TaO}_{\mathrm{x}}$ films may contribute to optimize the performance of insulating acoustic reflectors, we have simulated the acoustic transmittance of mirrors composed of nine alternated layers of porous $\mathrm{SiO}_{2}$ and $\mathrm{TaO}_{\mathrm{x}}$ films and compared it with that of conventional AlNbased mirrors. The simulations, shown in Fig. 7, suggest that even for the lowest values of the mass density and acoustic velocity, $\mathrm{TaO}_{\mathrm{x}}$-based mirrors exhibit lower transmission coefficients in a wider frequency band that AlN-based reflectors. Additionally, the dispersion of the values of the mass density and acoustic velocity does not affect significantly the performance of the reflectors in the middle of the band.

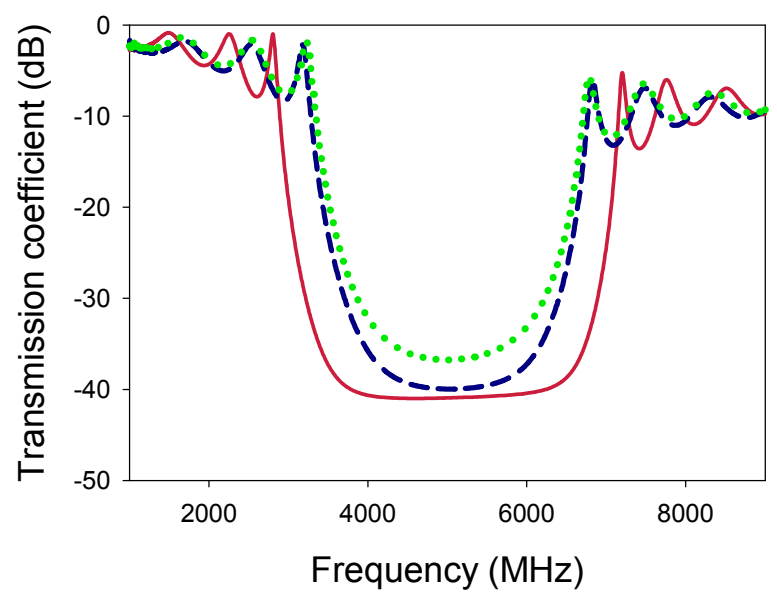

Figure 8. Simulated transmision coefficient of acoustic reflectors composed of nine porous $\mathrm{SiO}_{2} / \mathrm{TaO}_{\mathrm{x}}$ layers using a) the greatest values of $\rho$ and $v_{\mathrm{s}}$ (red solid line) and $\mathrm{b}$ ) the smallest values of $\rho$ and $v_{\mathrm{S}}$ (blue dashed line) compared to that of conventional $\mathrm{SiO}_{2} / \mathrm{AlN}$ reflectors (green dotted line).

Preliminary results on the performance of AlN-based SMRs using insulating $\mathrm{TaO}_{\mathrm{x}} / \mathrm{SiO}_{2}$ acoustic reflectors yield quality factors up to 500 at $8 \mathrm{GHz}$.

\section{CONCLUSIONS}

In this paper we assessed the acoustic properties of $\mathrm{TaO}_{x}$ films deposited at room temperature by reactive pulsed-DC sputtering. The sound velocity derived from picosecond measurements and the frequency response of BAW test devices slightly depends on the thickness of the films, which has been associated to their different structure. Thinner films appear to be amorphous whereas films $600 \mathrm{~nm}$-thick and above tend to exhibit some nanocrystallites. The typical sound speed in films with thickness below $400 \mathrm{~nm}$ is around 5000 $\mathrm{m} / \mathrm{s}$. The mass density of the $\mathrm{TaO}_{\mathrm{x}}$ films was assessed by Xray reflectometry; the average value is $7600 \mathrm{~kg} / \mathrm{m}^{3}$, around $93 \%$ of the nominal density of $\mathrm{Ta}_{2} \mathrm{O}_{5}$ films. The typical acoustic impedance of the films is $38 \times 10^{6} \mathrm{~kg} \cdot \mathrm{m}^{-2} \cdot \mathrm{s}^{-1}$, which is greater than that of AlN. Combined with a low acoustic impedance material, such as porous $\mathrm{SiO}_{2}, \mathrm{TaO}_{\mathrm{x}}$ films allow to fabricate all dielectric acoustic reflectors with good performances for $\mathrm{GHz}$ filtering applications. 


\section{ACKNOWLEDGMENT}

This work has been supported by the Ministerio de Ciencia e Innovación of Spain through project MAT2010-18933, by the Comunidad de Madrid and the UPM through the IV PRICIT programme and by the European Union through the European Regional Development Fund (FEDER).

\section{REFERENCES}

[1] R. Ruby, "Review and Comparison of Bulk Acoustic Wave FBAR, SMR Technology", in Proc. 2007 IEEE International Ultrasonics Symposium, New York 2007, 1029-10407.

[2] K.M. Lakin, K.T. McCarron, R.E. Rose, "Solidly Mounted Resonators and Filters", in Proc. 1995 IEEE International Ultrasonics Symposium, Seattle 1995, pp. 905-908.

[3] S. Marksteiner, J. Kaitila, G.G. Fattinger, and R. Aigner, "Optimization of Acoustic Mirrors for Solidly Mounted BAW Resonators", in Proc. 2005 IEEE International Ultrasonics Symposium, Rotterdam 2005, vol. 1, pp 329-332.

[4] J. Enlund, D. Martin, V. Yantchev and I. Katardjiev, "Solidly mounted thin film electro-acoustic resonator utilizing a conductive Bragg reflector", Sensors and Actuators A 141 (2008) pp. 598-602.

[5] A. Reinhardt, N. Buffet, A.Shirakawa, J. B. David, G. Parat, M. Aid, S. Joblot, P. Ancey, "Simulation of BAW resonators frequency adjustment", in Proc. 2007 IEEE International Ultrasonics Symposium, New York 2007, pp. 1444-1447.

[6] J. Olivares, E. Wegmann, M. Clement, J. Capilla, E. Iborra, and J. Sangrador, "Wide Bandwidth Bragg Mirrors for Multi-band Filter Chips", in Proc. 2009 IEEE International Ultrasonics Symposium, Rome 2009, pp. 2119-2122.

[7] C.-J. Chung, Y.-C. Chen, C.-C. Cheng, K.-S. Kao, "Fabrication and frequency response of solidly mounted resonators with $1 / 4 \lambda$ mode configuration", Thin Solid Films 516 (2008) pp. 5277-5281

[8] R. Aigner, J. Kaitila, J. Ella, L. Elbrecht, W. Nessler, M. Handtmann, T.-R. Herzog, and S. Marksteiner, "Bulk-Acoustic-Wave Filters: Performance Optimization and Volume Manufacturing”, in Proc. 2003 IEEE International MTT-S Digest, Philadelphia 2003, pp. 2001-2004.

[9] S.H. Kim, J.H. Kim, J.K. Lee, S.H. Lee, K. H. Yoon, "Bragg reflector thin film resonator using aluminium nitride deposited by rf sputtering", in Proc. 2000 IEEE Microwave Conference Asia-Pacific, Sidney 2000, pp. 1535-1538.

[10] J-W. Lobeek, R. Strijbos, A. Jansman, N. X. Li, A. B. Smolders, and N. Puisford "High-Q BAW Resonator on $\mathrm{Pt} / \mathrm{Ta}_{2} \mathrm{O}_{5} / \mathrm{SiO}_{2}$-based Reflector Stack", in Proc. 2007 IEEE International MTT-S Digest, Hawaii 2007, pp. 2047- 2050.

[11] H.P.Loebl, C.Metzmacher, R.F.Milsom, R.Mauczok, W.Brand, P.Lok, A.Tuinhout, F. Vanhelmont, "Narrow Band Bulk Acoustic Wave Filters", in Proc. 2004 IEEE International Ultrasonics Symposium, Montréal 2004, pp. 411-415.

[12] P. Emery, G. Caruyer, R. Vélard, N. Casanova, P. Ancey, and A Devos, "Picosecond Ultrasonics: An original tool for physical characterization of Bragg reflectors in bulk acoustic wave resonators" in Proc. 2005 IEEE International Ultrasonics Symposium, Rotterdam 2005, pp. 906-909.

[13] A.P. Huang, S.L. Xu, M.K. Zhu, B. Wang, H. Yan, "Crystallization control of sputtered $\mathrm{Ta}_{2} \mathrm{O}_{5}$ thin films by substrate bias", Appl. Phys. Lett. vol 83, $\mathrm{n}^{\circ} 16, \mathrm{pp} .3278-3280$ (2003).

[14] A. C. Ferrari, A. Libassi, B. K. Tanner, V. Stolojan, J. Yuan, L. M. Brown, S. E. Rodil, B. Kleinsorge, J. Robertson "Density, sp3 fraction, and cross-sectional structure of amorphous carbon films determined by $\mathrm{x}$-ray reflectivity and electron energy-loss spectroscopy", Phys. Rev. B 62, pp. 11089-11103

[15] P. Zaumseil, Reflectivity software RCRefSimW, Version 1.09 Innovations for high performance Microelectronics. Frankfurt Germany. (http://www.ihp-microelectronics.com)

[16] J.F. Rosenbaum, Bulk Acoustic Wave Theory and Devices, Artech House, Boston 1988.
[17] J. Olivares, E. Wegmann, J. Capilla, E. Iborra, M. Clement, L. Vergara, and R. Aigner, "Sputtered $\mathrm{SiO}_{2}$ as Low Acoustic Impedance Material for Bragg Mirror Fabrication in BAW Resonators", IEEE Trans. Ultrason. Ferr. Freq. Control., vol. 57 n ${ }^{\circ}$ 1, January 2010, pp. 23-29.

[18] P. Emery, A. Devos, P Ancey "Picosecond Ultrasonics: the preferred tool for BAW characterization" Proc. 2008 IEEE International Ultrasonics Symposium, Beijin 2008, pp. 2205-2208.

[19] A. Devos and R. Côte, "Strong oscillations detected by picosecond ultrasonics in silicon: Evidence for an electronic-structure effect", Phys. Rev. B 70, 125208 (2004).

[20] A. Devos and R. Côte, "Refractive index, sound velocity and thickness of thin transparent films from multiple angles picosecond ultrasonics", Rev. Sci. Instrum. 76, 053906 (2005). 